\title{
Cognition, Emotion and Behaviour: Addressing the Relationship Between Executive Functions and Decision-Making
}

\author{
Mini Review \\ Volume 2 Issue 4- 2021 \\ Author Details \\ Gonzalez Aguilar Maria Josefina, Rodriguez López de Osornio Sofía, Lynch Sofía, Mennella Paula, Alba \\ Ferrara Lucía \\ Facultad de Ciencias Biomédicas, Universidad Austral, Argentina \\ *Corresponding author \\ María Josefina Gonzalez Aguilar, Facultad de Ciencias Biomédicas, Universidad Austral, Av. Juan Domingo Perón 1500, B1629, \\ Pilar, Buenos Aires, Argentina \\ Article History \\ Received: October 30, 2021 Accepted: November 26, 2021 Published: November 30, 2021

\begin{abstract}
Executive functions are a complex and heterogeneous group of concepts that refer to a set of diverse cognitive abilities such as working memory, cognitive flexibility, planification, reasoning, problem-solving and inhibition. Moreover, decision-making may be described as a pattern that a person uses when he or she is facing a situation where they must lean towards an option: people tend to choose one or another option considering the risks and benefits these options offer. There is evidence supporting that executive functions are associated with the way people make their decisions. The main aim of the present study is to review and update these concepts reporting evidence from the literature on the association between the cognitive, emotional, and behavioral aspects of decisionmaking.
\end{abstract}

\begin{abstract}
Mini Review
To define executive functions is a difficult task, as this concept refers to a set of complex cognitive skills which generally focuses on five specific abilities $[1,2]$. These main skills are working memory, as the ability to retain and manipulate data mentally; cognitive flexibility, as the ability to generate new solutions for a more efficient adaptation to the world; planification, understood as the ability to think and select an efficient way to reach a goal; reasoning, as the ability to create and think abstractly; problem-solving, known as the ability to analyze a situation and find a suitable solution for it; and inhibition, as the ability to act accordingly to a certain situation postponing a more automatic behavior [3-5].
\end{abstract}

Decision-making is the action by which a choice is made among the available options required to solve different situations, and is essential to everyday life activities, as people are constantly faced by situations that require them to make a choice. Risky decisions are decisions based on the rewarding consequences, while neglecting the possibility of a big loss. These risky decision pattern may become maladaptive over time [6]. There is a wide range of factors that come into play when someone makes a decision, such as risk-taking, emotion regulation and self-regulation. There are certain individual differences, like age and gender, that make a person more prone to risk-taking behaviors. For example, men tend to make more risky decisions than women in situations involving financial or health issues [7], whereas women make more risky decisions in the social domain [8]. Neurobiological [9] and psychosocial differences [10] had reported evidence addressing this gender differences. On the other hand, adolescents are more prone to engage in riskier behaviors compared to adults [11]. This phenomenon has been explained by neurobiological and psychological models which highlight the role of brain development in one hand [12] and the importance of experience-based development on the other [13,14]. Mckewen [15] propose that individual differences in cognitive control, rather than age itself, play a crucial role in risky decision-making. In line with this, there is evidence on how poor executive function in young adults is associated to higher risk-taking behaviors [16], such as risky sexual behavior [17], alcohol addiction [18], and antisocial behaviors [19]. The question then would be if it is age, executive function in general, or both factors, what may explain the differences in decision-making patterns.

A recent study concluded that age itself may not be directly associated 
with risky decision-making, but that there is evidence that risk-taking propensity might peak during early adulthood [11]. Another study [16] analyzed the relationship between executive function and risk taking in young adults, revealing a strong relationship between these two constructs. For example, better performance in classic executive functioning tasks was associated with fewer antisocial acts, substanceuse, and less risky-sexual behaviors.

Steinberg (2008) proposed a theoretical framework for decision making based on the Dual System Model. According to this model, there are two neural systems implicated in decision making. One of them, the emotional system, is reward seeking, as opposed to the rational/logical system which has a cognitive control role. From a developmental point of view, the first one is acquired at an earlier age compared to the second one, which reaches maturity at young adulthood [20,21].

Executive functions are traditionally divided into cold and hot skills. The cold functions are used in the solution of abstract and decontextualized problems that require behavioral inhibition, action planning, abstract reasoning, etc., while the hot functions act in situations where emotions play a fundamental role [22]. Hot executive functions are involved in decision-making in situations of uncertainty and are concerned with the regulation of affect and motivation (limbic system), that is, with the emotional significance of stimuli [23]. Most studies support the hypothesis of a difference between hot and cold executive functions as a matter of degree. In fact, both are involved in any decision making, although to a greater or lesser extent, depending on the task that is being carried out.

Moreover, Morawetz [24] added the role of emotion regulation in executive functions: they found that the ventrolateral prefrontal cortex serves as a shared neural foundation for emotion regulation and risky decision-making. In turn, it accounts for the effective decrease in the experience of negative emotions and risk-taking brought on by the regulation of incidental emotion. This relationship between emotion and decision-making was confirmed by other studies [25-27].

Decision-making can be understood in two forms: under ambiguity and under risk. Decision-making is held under ambiguity when the alternatives are known but their outcomes are not and, therefore, cannot be predicted [28]. On the other hand, decision-making under risk is given when the alternatives and their outcomes are known. With this information, people who make decisions under risk generate a response pattern after a continuous and systematic analysis of the outcomes (rewards and punishments) they received along their decision-making task [3,29]. Neuropsychological assessment may contribute to a better understanding of the relationship between decision-making, cognitive skills (such as execute functions), emotion, and behaviour. In this way, neuropsychological tools such as the Iowa Gambling Task (IGT) and the Game of Dice Task (GDT) are useful to understand decision-making. The IGT was developed by Bechara, Damasio, Damasio, \& Anderson [30] and is one of the most used tasks used to evaluate decision-making under ambiguity, whereas decisionmaking under risk can be assessed with GDT, developed by Brand [31].

Decision-making is affected in disorders such as obsessive-compulsive disorder, addictions, eating disorders, and attention deficit [32]. Therefore, studying the relationship between decision-making, behaviour and executive functions could allow a new approach in the treatment of these and other conditions. Future studies may specifically analyze the association between the different aspects of decision-making (with tasks such as the IGT or the DGT), executive functions, emotional response, risky/non-risky behaviors (such us alcohol consumption or drug use), and different psychological disorders, as the literature shows that these domains may be highly associated.

\section{References}

1. Cicerone KD, Dahlberg C, Kalmar K, Langenbahn DM, Malec JF, et al (2000) Evidence-based cognitive rehabilitation: Recommendations for clinical practice. Archives of Physical Medicine and Rehabilitation 81(12): 1596-1615.

2. Kennedy MRT, Coelho C, Turkstra L, Ylvisaker M, Moore Sohlberg M, et al. (2008) Intervention for executive functions after traumatic brain injury: A systematic review, meta-analysis and clinical recommendations. Neuropsychological Rehabilitation 18(3): 257-299.

3. Brand M, Labudda K, Markowitsch HJ (2006) Neuropsychological correlates of decision-making in ambiguous and risky situations. Neural Networks 19(8): 1266-1276.

4. Cristofori I, Cohen-Zimerman S, Grafman J. Executive functions. In: Handbook of Clinical Neurology. New York: Elsevier; pp: 197-219.

5. Miyake A, Friedman NP, Emerson MJ, Witzki AH, Howerter A, et al. (2000) The Unity and Diversity of Executive Functions and Their Contributions to Complex "Frontal Lobe" Tasks: A Latent Variable Analysis. Cognitive Psychology 41(1): 49-100.

6. Nigg JT (2017) Annual Research Review: On the relations among selfregulation, self-control, executive functioning, effortful control, cognitive control, impulsivity, risk-taking, and inhibition for developmental psychopathology. Journal of Child Psychology and Psychiatry and Allied Disciplines 58(4): 361-383.

7. Morgenroth T, Fine C, Ryan MK, Genat AE (2017) Sex, Drugs, and Reckless Driving: Are Measures Biased Toward Identifying Risk-Taking in Men? Social Psychological and Personality Science 9(6): 744-753.

8. Zou X, Scholer AA (2016) Motivational Affordance and Risk-Taking Across Decision Domains. Personality and Social Psychology Bulletin 42(3): 275-289.

9. van den Bos R, Homberg J, de Visser L (2013) A critical review of sex differences in decision-making tasks: Focus on the Iowa Gambling Task. Behavioural Brain Research 238: 95-108.

10. Villanueva-Moya L, Expósito F (2020) Spanish Women Making Risky Decisions in the Social Domain: The Mediating Role of Femininity and Fear of Negative Evaluation. Frontiers in Psychology p. 11.

11. Ogilvie JM, Shum DHK, Stewart A (2020) Executive Functions in Late Adolescence and Early Adulthood and Their Relationship with RiskTaking Behavior. Developmental Neuropsychology 45(7-8): 446-468.

12. Casey BJ, Jones RM, Hare TA (2008) The Adolescent Brain. Ann N Y Acad Sci 1124: 111-126.

13. Reyna VF, Wilhelms EA, Mccormick MJ, Weldon RB (2015) Development of Risky Decision Making: Fuzzy-Trace Theory and Neurobiological Perspectives. Child Development Perspectives 9(2): 122-127.

14. Romer D, Reyna VF, Satterthwaite TD (2017) Beyond stereotypes of adolescent risk taking: Placing the adolescent brain in developmental context. Developmental Cognitive Neuroscience 27: 19-34.

15. McKewen M, Skippen P, Cooper PS, Wong ASW, Michie PT, et al (2019) Does cognitive control ability mediate the relationship between reward-related mechanisms, impulsivity, and maladaptive outcomes in adolescence and young adulthood? Cognitive, Affective and Behavioral Neuroscience 19(3): 653-676.

16. Reynolds BW, Basso MR, Miller AK, Whiteside DM, Combs D (2019) Executive function, impulsivity, and risky behaviors in young adults. Neuropsychology 33(2): 212-221.

17. Ross JM, Duperrouzel J, Vega M, Gonzalez R (2016) The Neuropsychology of Risky Sexual Behavior. Vol. 22, Journal of the International Neuropsychological Society. Cambridge University Press 22(6): 586-594.

18. Noël X, van der Linden M, D’Acremont M, Bechara A, Dan B, et al. (2007) 
Alcohol cues increase cognitive impulsivity in individuals with alcoholism Psychopharmacology 192(2): 291-298.

19. Goldstein RB, Chou SP, Saha TD, Smith SM, Jung J, et al. (2017) The epidemiology of antisocial behavioral syndromes in adulthood: Results from the National Epidemiologic Survey on Alcohol and Related Conditions-III. Journal of Clinical Psychiatry 78(1): 90-98.

20. Steinberg L (2008) A social neuroscience perspective on adolescent risktaking. Dev Rev 28(1): 78-106.

21. Steinberg L (2010) A dual systems model of adolescent risk-taking. Dev Psychobiol 52(3): 216-224.

22. Chambers RA, Potenza MN (2003) Neurodevelopment, impulsivity, and adolescent gambling. J Gambl Stud 19(1): 53-84.

23. Bechara A (2004) The role of emotion in decision-making: Evidence from neurological patients with orbitofrontal damage. Brain Cogn 55(1): 30-40.

24. Morawetz C, Mohr PNC, Heekeren HR, Bode S (2019) The effect of emotion regulation on risk-taking and decision-related activity in prefrontal cortex. Soc Cogn Affect Neurosci 14(10): 1109-1118.

25. Yang Q, Gu R, Tang P, Luo YJ (2013) How does cognitive reappraisal affect the response to gains and losses? Psychophysiology 50(11): 1094-103.

26. van't Wout M, Chang LJ, Sanfey AG (2010) The Influence of Emotion
Regulation on Social Interactive Decision-Making. Emotion 10(6): 815821

27. van 't Wout M, Faught S, Menino D (2013) Does interoceptive awareness affect the ability to regulate unfair treatment by others? Front Psychol 4 : 880

28. Bechara A, Damasio H, Tranel D, Damasio AR (2005) The Iowa Gambling Task and the somatic marker hypothesis: some questions and answers. Trends in Cognitive Science 9(4): 159-162.

29. Özdes A (2020) Yaşlanma ve Karar Verme Süreçleri: Duygu Düzenlemenin Rolü. Psikiyatride Guncel Yaklasimlar - Current Approaches in Psychiatry 12(3): 382-395

30. Bechara A, Damasio AR, Damasio H, Anderson SW (1994) Insensitivity to future consequences following damage to human prefrontal cortex. Cognition 50(1-3): 7-15.

31. Bechara A, Damasio AR (2005) The somatic marker hypothesis: A neural theory of economic decision. Games and Economic Behavior 52(2): 336372.

32. Dunn BD, Dalgleish T, Lawrence AD (2006) The somatic marker hypothesis: A critical evaluation. Neuroscience and Biobehavioral Reviews 30(2): 239-271. 